\title{
La lección de Auschwitz
}

\section{FERNANDO BÁRCENA y JOAN-CARLES MÈLICH}

Universidad Complutense de Madrid

Universidad Autónoma de Barcelona

\begin{abstract}
Éste es un mundo aparte, sin parecido a ningún otro, con leyes, usos, hábitos y costumbres propios: una casa de los muertos vivientes, una vida como no la hay en otro lugar, y gente sin igual. Es este mundo aparte el que me dispongo a describir.
\end{abstract}

F. Dostoyewski, La casa de los muertos.

\section{Introducción: La transmisión de Auschwitz}

El objetivo de este artículo es mostrar cómo se ha recibido Auschwitz, el acontecimiento que ha desgarrado la historia reciente, ${ }^{1}$ en los distintos ámbitos de la cultura (poesía, pintura, música, cine....) No nos ocuparemos, por tanto, de la recepción tal y como ha tenido lugar en la sociedad en general, sino especialmente entre algunos intelectuales y artistas. La selección de autores y textos no podrá ser, obviamente, exhaustiva. ${ }^{2}$ Nuestra aproximación tendrá lugar desde el punto de vista y desde los intereses (obviamente, también podríamos hablar de prejuicios) de la filosofía de educación.

Una filosofía de la educación hoy, después de Auschwitz, tiene que ser especialmente sensible a la cuestión de cómo los acontecimientos rompen el tiempo y obligan a repensar radicalmente todas nuestras categorías interpretativas. $\mathrm{Al}$ mismo tiempo, la cuestión de elucidar el modo en que los acontecimientos son recibidos en una determinada comunidad, el lenguaje en el que son transmitidos, así como la recepción de los acontecimientos en el seno de una tradición que ha sido literalmente rota y pulverizada por ellos, resulta esencial a toda filosofía de la educación que entienda que el ser humano es, para bien o para mal, un ser ineludiblemente histórico, y, por lo tanto, un ser que vive en tiempo y espacio, que siempre es un tiempo y un espacio concretos. ${ }^{3}$ Pues bien, nuestro tiempo y nuestro espacio no pueden ser pensados sin Auschwitz, pero al mismo tiempo no pueden -quizá- ser pensados en Auschwitz, porque Auschwitz ha roto nuestro lenguaje, el lenguaje en el que radicalmente se transmitían las experiencias. ${ }^{4}$ Esta es una paradoja esencial a la recepción de Auschwitz en la cultura occidental que una filosofía de la educación hoy debería poder dar cuenta. ${ }^{5}$

Ante el acontecimiento de Auschwitz, el silencio es un lenguaje. Ante Auschwitz, el silencio no es necesariamente el fracaso de la comunicación. El silencio ante Auschwitz puede ser el olvido, obviamente, pero también puede significar una forma de expresar lo indecible, lo incomunicable a través de otras formas de expresión. ${ }^{6} \mathrm{La}$ recepción de Auschwitz, el silencio de Auschwitz, es un acto de aprendizaje. Sin el aprendizaje del silencio de Auschwitz no hay recepción posible. Hay que ser capaz de transmitir la palabra silenciosa del que no puede hablar, hay que aprender 
a escuchar al que se le ha arrebatado la palabra y la condición humana, hay que dejar hablar al que tiene "la palabra silenciada", "la palabra arrancada al silencio", como escribe Paul Celan en su poema "Argumentum e silentio"7.

Pero un problema fundamental en la recepción de Auschwitz es, precisamente, que la recepción tiene lugar en la ruptura de la tradición: nuestra herencia no tiene ningún testamento. Como decía Hannah Arendt, Auschwitz ha roto todos nuestros criterios, todas nuestras categorías de pensamiento y de juicio moral. Volvemos entonces a la pregunta inicial. ¿Cómo recibir el acontecimiento de Auschwitz? ¿Desde qué lenguaje transmitir esta experiencia? ¿Cómo hacer memoria que no se puede narrar? ¿Desde qué lenguaje recibirla?

$\mathrm{Si}$ es cierto que toda historia es una interpretación de la historia, no lo es menos el hecho de que toda interpretación sólo puede realizarse en el seno de una $\mathrm{u}$ otra tradición, de un $\mathrm{u}$ otro lenguaje, de un u otro universo simbólico, de un $\mathrm{u}$ otro imaginario. Pero si precisamente Auschwitz se caracteriza por la ruptura, entonces hay que buscar nuevas formas de expresión (el caso de la poesía de Paul Celan sería ejemplar), y nuevas formas de recepción.

Desde nuestro punto de vista, respecto a la cuestión más directamente pedagógica de la recepción, es fundamental, como ya hemos dicho antes, la cuestión del silencio. Recibir la experiencia de Auschwitz significa ser capaz de escuchar el silencio. Este silencio, este vacío es el que llama la atención poderosamente a Claudio Magris en la gran plaza de Mauthausen: "La imagen más terrible, más aún quizás que la cámara de gas, es la gran plaza en la que los prisioneros eran reunidos y alineados para la llamada. La plaza está vacía, soleada, sofocante. Nada mejor que este vacío para explicar la imposibilidad de representar lo que sucedió entre estas piedras"8.

\section{El silencio como límite simbólico}

A la luz de las consideraciones precedentes, se puede plantear de dos modos la actividad de recepción de lo que resulta espantoso y quizá la cultura occidental no quiere ver por el daño y la vergüenza que aún provoca. El primer modo es aquél en el que la pregunta principal es esta: ¿́cómo debemos recibir "después de Auschwitz" ese acontecimiento atroz los que nacimos en el tiempo, justamente, de “después de...”? La segunda forma adopta esta otra formulación interrogativa: ¿cómo se recibió entre los artistas e intelectuales la noticia de la magnitud de la barbarie en el tiempo que inmediatamente siguió al Holocausto en las décadas posteriores?

El primer interrogante contiene un doble valor o un doble punto de vista valorativo: ético y pedagógico. Se trata de saber cómo hemos de recibir la lección de Auschwitz y sus enseñanzas, la tremenda herencia del sufrimiento que este acontecimiento nos transmite, y saber también cómo debemos prepararnos (educarnos, formar nuestra mente y nuestra conciencia) para evitar su repetición.

La segunda modalidad obliga a un estudio analítico y a una reconstrucción histórica capaz de exponer la evolución de la conciencia intelectual y artística europea al ir tomando conocimiento de la magnitud de la tragedia, y explorar el trayecto que va desde el silencio inicial hasta la banalización de Auschwitz .

En la base de ambas preguntas es posible encontrar, por una parte, la preocupación, formulada entre otros por Reyes Mate, relacionada con los motivos que justifican el recuerdo de lo tremendo. En De Atenas a Jerusalén, se pregunta si tiene algún sentido el recuerdo de Auschwitz. La respuesta a esta pregunta pasa por reconocer que después de Auschwitz los hombres y las sociedades que forman no pare- 
cen más ricos en humanidad y por el hecho, central a nuestro juicio, de que lo que murió en los campos de exterminio fue la idea del hombre que se había venido concibiendo por la tradición del humanismo clásico $^{10}$.

Pero, por otro lado, también cabe darse cuenta de una paradoja que es inherente a la labor de transmisión en el contexto de la cultura occidental y de las actuales sociedades modernas. El mundo de la cultura, y el de la civilidad, se inscribe en la palabra y en la escritura. Es desde este mundo, por así decir, desde el cual los supervivientes dan testimonio de su experiencia vivida. Al hacerlo así, los supervivientes transforman su experiencia dolorosa en relato, esto es, en una especie de ficción. Y sin embargo, las palabras que pronuncian y su escritura remiten a algo que está más allá, o mejor dicho más acá, del mundo libre, del mundo civilizado y cultural: remiten a la experiencia de lo inhumano, de la anti-cultura. Al mundo donde la cultura es puesta radicalmente en cuestión y es de hecho destruída. Podemos entonces hablar de un fracaso radical de cualquier intento de dar testimonio, y este fracaso es una cierta experiencia de la vergüenza, no ya del superviviente que ha sobrevivido al infierno, sino la vergüenza de su escritura testimonial, la vergüenza misma de la literatura. Su escritura es, por tanto, una escritura avergonzada, una escritura-testimonio que no tiene más remedio que referirse a lo que no debería ser nombrado y una escritura que debe asumir el compromiso por ficcionalizar la memoria de lo vivido para, desde el mundo libre y desde el mundo de la palabra y la cultura, poder hablar, desde una irremisiblemente memoria herida, de todo lo que no es cultura. Por eso hemos en la escritura testimonial no todo puede ser dicho: aquí el silencio no es ausencia de comunicación, sino el límite simbólico de lo que debe escribirse o no, de lo que debe decirse o callarse.
Guiados por estas reflexiones, en lo que sigue hablaremos no tanto de lo que significa hablar de la memoria de los campos como de algunos espacios culturales en lo que esa memoria de Auschwitz ha dejado su huella perdurable. No tendría ningún sentido limitarnos a una lista, a un elenco de obras y títulos. Creemos que resulta mucho más interesante el hecho de seleccionar y de interpretar algunas obras y algunos autores que consideramos que resultan especialmente relevantes.

Nuestro interés es, principalmente, pedagógico, pues es a través del lenguaje, en toda la gama de sus formas expresivas dentro de la cultura, el medio a través del cual podemos transmitir la memoria de ese horror, y el de otros todavía vigentes. De modo preferente, hemos elegido aquéllas producciones culturales elaboradas en el mismo tiempo del horror o inmediatamente después. Y nos hemos guiado por el criterio de que esas producciones - pintura, poesía, música o cine- se pueden entender como textos que se dan a leer y que, sobre todo, por el testimonio terrible que nos transmiten, exigen una lectura y una interpretación sumamente atenta y responsable, una lectura seria, podemos decir con George Steiner. Ahí se contiene una "presencia real", una presencia que nos da a pensar, que nos permite hacer experiencia, y que nos puede permitir darnos cuenta que, a partir de la segunda mitad del siglo $\mathrm{XX}$, algo se rompió en dos, entre un antes y un después: el acontecimiento de Auschwitz. Por eso mismo, nos hemos centrado, sobre todo en la Poesía (Paul Celan), en la Pintura (Zoran Music), en la Música (Oliver Messiaen, Arnold Schönberg) y en el Cine (Claude Lanzmann). El último punto lo hemos reservado al espacio estrictamente pedagógico, y en él intentaremos explicar por qué Auschwitz puede entenderse como un acontecimiento educativo radical. ${ }^{11}$ 


\section{Los espacios de recepción}

La cuestión de la indecibilidad de Auschwitz, el carácter atroz de algo quizá imposible de representarse, de imaginarse o de narrarse no es algo relacionado tanto con el hecho de decir la verdad como con la forma de decirla, de cómo decirla: "El problema aquí no es tampoco simplemente contar la verdad, sino cómo contarla, porque no resulta creíble, ni imaginable"12.

Esta es una experiencia común a todos los supervivientes. Esa es la cuestión: para contar la verdad de aquello que resulta inimaginable, el único modo es la necesaria mediación del arte, en su sentido más amplio. Junto a los documentos que nos informan de datos sobre lo que allí aconteció, con el propósito de incrementar nuestro grado de información, es preciso también ponernos en situación de imaginar en lo que pudo consistir el sufrimiento de las víctimas y de los supervivientes. J-F. Forges señala en este punto la necesidad de aprender a dominar la emoción, para tomar conciencia profunda de ese dolor y abrirse a una comprensión capaz de producir compasión. Y ésta se logra no sólo cuando leemos los testimonios de los supervivientes, o cuando un antiguo deportado nos habla de su propia experiencia: la obra de arte es una mediación necesaria para la transmisión y para la recepción de Auschwitz. ${ }^{13}$

Podemos decir que, en este sentido, el arte ha sobrevivido a Auschwitz, pero se trata de un arte distinto, un arte a través del que se puede mostrar el horror. Sólo los "artistas" de la dimensión de Arnold Schönberg y Claude Lanzmann, de Zoran Music o de Paul Celan, por poner tan sólo unos pocos ejemplos significativos, pueden afrontar el extraordinario proyecto de recrear, de transmitir el mundo del Lager y de la Shoah. ${ }^{14}$ Así que, como comentaba Imre Kertész en una entrevista con Ger- hard Moser, ya que Auschwitz ha influido tan notablemente en el arte, es preciso quizá concebirlo no sólo como un juego o mero ornamento, sino como una tarea digna y seria, como "la actividad propiamente metafísica del hombre". ${ }^{15}$

\subsection{Poesía}

Como en alguna ocasión se ha dicho, la poesía de Paul Celan, especialmente su poema Todesfuge $e^{16}$, constituye un "lamento moral del Arte contra la Historia". ${ }^{17} \mathrm{El}$ conjunto de su obra poética es, como señala Traverso, una "necesidad casi biológica de expresión", y su escritura se puede inscribir, sin duda, contra las tesis de una pretendida incomunicabilidad o indecibilidad del aniquilamiento y del exterminio ${ }^{18}$.

Todesfuge lo escribió Celan, en su primera versión, en torno a 1944-45, entre Czernovitz y Bucarest, y tras una primera edición en Viena (1948) en un libro titulado Der Sand aus den Urnen (La arena de las urnas) llena de erratas tipográficas, es publicado en su versión definitiva en 1952 en su libro Mohn und Gedächtnis (Amapola y memoria). Celan se sorprendió de la acogida inmediata del poema, una acogida que tuvo como efecto enredarle dentro de la querella entre "poesía comprometida" y "poesía pura".

El poema es de enorme importancia y, dentro de lo que cabe, desde luego de los más accesibles desde el punto de vista interpretativo y hermenéutico. De hecho se le ha calificado como "el mejor poema alemán de la posguerra", aquél precisamente que resolvió la imposibilidad de escribir poesía después de Auschwitz, de que había hablado Adorno.

En términos generales, la crítica y los especialistas en la obra poética de Celan tienden a destacar en Todesfuge dos fuentes temáticas principales en la tradición literaria y musical alemana: la Fuga y la Muerte. Fuga, desde luego, en su sentido musical. Traverso comenta que no es de 
extrañar que Celan haya conservado el espíritu de las composiciones de Schubert, Mahler e incluso Wagner, así como la referencia más explícita al Fausto de Goethe ("tu cabello de oro Margarete"). Pero sobre todo, el poema tiene su fuente principal de inspiración en un hecho real, que el amigo de Celan, Petre Solomon, anota en la publicación que del poema hace en 1944 en la revista de Bucarest Contemporanul: en el campo de exterminio de Lublin-Majdanek, se obligaba a tocar a una orquesta formada por judíos y cantar nostálgicas canciones mientras otros cavaban sus tumbas. De hecho Solomon tituló el poema en rumano Tangoul Mortii (Tango de muerte). Sea como sea, como en $L a$ muerte y la doncella de Schubert, o en el Réquiem alemán, de Brahms, "se pone en conexión la nada y el orden, las paradojas de la aniquilación, la armonía para expresar una aflicción externa" ${ }^{\prime 19}$ :

Negra leche del alba la bebemos de tarde

La bebemos a mediodía de mañana la bebemos de noche

Bebemos y bebemos

Cavamos una fosa en los aires no se yace allí estrecho

Vive un hombre en la casa que juega con las serpientes que escribe

En la casa vive un hombre

que escribe al oscurecer a Alemania tu pelo de oro Margarete

lo escribe y sale de la casa y brillan las estrellas silba a sus mastines

silba a sus judíos hace cavar una fosa en la tierra

nos ordena tocad a danzar

En Celan los poemas se estrechan. Como si se tratase de una lengua astillada. Astillada a propósito. Las astillas de la lengua con las que Celan escribe sus poemas son esas palabras, escuetamente palabras, breves si es posible, como desnudas y no acompañadas de otras partículas. Escribe como queriendo mostrar, en la forma en que escribe sus poemas, que la lengua hay que inventarla de nuevo. O mejor: como queriendo purificar cada frase, cada palabra, cada vocablo. Limpiar la lengua, la lengua alemana, la lengua destruída en parte por quienes empleaban palabras hermosas para designar cosas terribles.

Y es que quizá Celan sabía que la guerra hace de un hombre corriente un poeta. Como si sólo a través del poema pudiese intentarse el milagro de humanizar, no lo inhumano, sino lo tratado inhumanamente. Así, el poeta Celan practica su lengua desde una cierta memoria, y no solamente la suya, sino la memoria de los otros. Construye su identidad de poeta desde el recuerdo del otro del cual habla en su poema, del otro ausente, del otro que ya no está, como queriendo volver más humana su ausencia y menos muerte su muerte haciéndole presente en la belleza del poema. En Celan, ¿acaso la poesía no es memoria del ausente y sus palabras no caminan hacia el otro que se representa en el poema? El yo del poeta como representación de la tragedia del otro.

En Celan, por tanto, la poesía es a menudo un homenaje a la humanidad, un homenaje que celebra, no la ausencia, sino la presencia ausentada del otro. Ante la muerte del otro, el poeta canta preservando su memoria, resumiéndola en un poema. Memoria poética ante el previsible olvido del otro. Con Celan, después de Auschwitz es en efecto posible escribir poesía, aunque quizá no está de más recordar -con Hans Mayer- hasta qué punto sigue amenazada todavía la labor poética, pese a los propios esfuerzos del poeta por rehabilitar la lengua poética, y no tanto porque el poema se resista a la escritura cada vez que se recuerda Auschwitz, "sino porque la cámara de gas no significa otra cosa que el exterminio de las minorías y consecuentemente del poeta"20.

Paul Celan sería el primer ejemplo, y tal vez el más claro, de la tesis que estamos 
defendiendo en este artículo: una auténtica transmisión de Auschwitz solamente es posible a través del silencio. Por descontado, que el silencio no es mutismo, sino todo lo contrario. El silencio es una forma fundamental de expresión. Porque el silencio es, precisamente, la forma de expresión que muestra el acontecimiento de Auschwitz en todo su dramatismo. La obra de Celan, tal vez como ninguna otra, es así capaz de expresar ese silencio.

\subsection{Pintura}

Probablemente la referencia más importante en la recepción de Auschwitz en el espacio de la pintura es la de Zoran Music. ${ }^{21} \mathrm{Y}$ lo es porque Music pinta sus dibujos no después, sino dentro de Dachau, una experiencia que le transformó de modo radical su punto de vista sobre el mundo y sobre sí mismo: "Aprendí -escribe Music- a ver las cosas de otro modo. Claro que no todo en mi pintura ha cambiado radicalmente más tarde. No es en absoluto una reacción ante el espanto que redescubriera la beatitud de la infancia (...) Tras haber visto uno u otro signo de cadáveres despojados, ante todo cadáveres despojados de todo lo superfluo (...) creo haber descubierto la horrorosa y trágica verdad que estaba destinado a captar"22.

Es la otra verdad: la verdad del cadáver desnudo, apilado, que muestra una verdad desnuda y desprovista de heroísmo: el "ser para la muerte". La visión del hombre de Zoran Music es una visión agrietada y aislada por la presencia de los campos y sus horrores, y ésta se incorpora indefectiblemente a sus obras. En su obra, como en su pintura de óleo sobre lienzo Hombre, de 1992, o bien en Nosotros no seremos los últimos, una acuarela de 1975, encontramos una figuración concentrada donde el dibujo -meras figuras- predominan sobre la variedad de los colores. Es sorprendente y característico de su obra pictórica que las líneas de sus figuras no defi- nen los límites de las partes de la composición, sino más bien las de masas de pintura que dan la impresión de sumergirse en la tela. Algunos críticos y analistas de su obra señalan que la dimensión trágica y la lección moral de las obras de Zoran Music estriba en este equilibrio que mantienen, entre la captación de lo real y la descomposición de lo visible, una vez que las formas pintadas llegan a formar parte de la superficie pintada. En sus figuras, difuminadas en el espacio pictórico hasta tornarse casi invisibles, se hace a veces imposible que se distingan los elementos de la composición, como si todo fuese un uno indiferenciado, un espacio total de formas mezcladas cuyos elementos integrantes no se distinguen entre sí. Un auténtico amontonamiento de formas, como los cadáveres apilados y amontonados en una fosa común tras su exterminio en masa.

Como hemos dicho, muchos de los dibujos de Music se crearon en el mismo campo de Dachau, a riesgo de su propia vida: "Comienzo a dibujar con temor -recuerda Music. Quizás esto me ayude a sobrevivir. Quizás llegue a descubrir en este peligro un cierto motivo para oponerme. Empiezo probando en secreto, en el cajón que tengo bajo el torno, con las cosas que veo en el camino hacia la fábrica (...) Más tarde dibujo en el campo mismo. Van pasando los días...y pronto me domina un ansia increíble y urgente de dibujar (...) Dibujo como si estuviera en trance, me aferro con mis últimas fuerzas a mis pedazos de papel. Estoy como cegado por la magnitud absurda de los campos de cadáveres". En este dibujar frenético es imprescindible captarlo todo, sin perder detalle, para que quede el testimonio trágico del arte: "iAl dibujar me aferro a miles de detalles! Qué trágica elegancia la que se desprende de estos cuerpos quebradizos. Los detalles llegan a hacerse sobrenaturales: las manos, los dedos afilados, los pies, las bocas semiabiertas que en una angustia extrema pare- 
cen querer sorber un resto de aire, los huesos apenas recubiertos por un pellejo blanco con un matiz violáceo apenas perceptible".

Las hojas de papel en las que Music hace sus dibujos no son un alegato contra algo, sino un testimonio, una crónica sobre el mal, escrita -dibujada- en el mismo infierno. Pintor, como se ha dicho, del silencio y del sobrecogimiento, los "personajes" de Music se debaten entre el ser y la nada, en el seno de una especie de espera irreal: "Vivíamos en un mundo que estaba más allá de todo lo que pueda imaginarse, en un universo absurdo, disparatado, irreal, un mundo que se encontraba posiblemente en otro planeta y que obedecía a reglas difícilmente creíbles, propias, y con un orden preciso y siniestro (...) En una apática espera, vivía en un paisaje de muertos y moribundos". Pero Music destaca, a través de trágicas preguntas, su inquietud por la posibilidad de poder mostrar, enseñar, sus obras: "Vida, muerte, para mí depende todo de esas hojas de papel. ¿Pero llegarán a verse alguna vez? ¿Podré llegar a enseñarlas?” Las preguntas acentúan la dimensión trágica de la verdad, la verdad del testimonio de Dachau y de los campos de exterminio. Son preguntas que versan tanto sobre la identidad como sobre la esperanza, no ya de Music, sino sobre la esperanza del mundo y de la humanidad misma: "Me pregunto: ¿Por qué estoy yo aquí? ¿Tiene algún sentido, sirve para algo haber vivido todo esto? ¿Podría este mundo carente de todo sentido ser quizá un purgatorio? ¿Me llevará a descubrir la verdad? ¿Acabaré reconociendo, yo que he quedado reducido a lo esencial, lo inútil que era todo lo que había hecho hasta entonces con mi vida?"

\subsection{Música}

La música es otro de los espacios culturales de recepción de Auschwitz. Creemos que resulta imprescindible referirse a dos autores y dos obras básicas, una compuesta y estrenada dentro de un campo, por un no judío, y otra, compuesta y estrenada en el exilio, por un judío. Nos referimos brevemente a Oliver Messiaen y su Quatuor pour la Fin du Temps (1940), y a Arnold Schönberg, con Ein Überlebender aus Warschau (1947).

Oliver Messiaen fue hecho prisionero en el verano de 1940. Internado en el campo de Görlitz (Silesia) compuso el Cuarteto para el fin del tiempo, que se estrenó dentro del campo en enero de 1941. La pieza consta de cuatro instrumentos (un piano, un violín, un clarinete y un violoncelo), los únicos de los que disponía Messiaen en el campo, que producen una de las músicas más desgarradoras de todo el siglo XX. El Cuarteto de Messiaen muestra, por un lado, el dramatismo del Lager, el sufrimiento de los seres humanos allí internados. Los instrumentos del Cuarteto parecen, a menudo, gritos desgarradores de dolor. Sin embargo, como en toda la obra del compositor francés, está presente la religiosidad y la esperanza. La obra termina con la "Alabanza a la inmortalidad de Jesús".

Algo notablemente distinto lo encontramos en Un superviviente de Varsovia, de Arnold Schönberg. En este caso no nos hallamos dentro del campo, ni en el guetto. Estamos en América, en el exilio. Schönberg compone una pieza magistral, en la que el texto es tan importante como la música. De hecho, Schönberg la compuso después de escuchar los relatos de los testimonios recibidos, como él mismo dijo, directa o indirectamente.

La expresividad de esta obra es suprema. Nos hallamos, probablemente, ante la cima de toda su producción. Un superviviente de Varsovia es, desde nuestro punto de vista, el ejemplo más claro de la recepción de Auschwitz en la música contemporánea. 
La obra tiene dos partes. En la primera de ellas, un narrador, que se expresa en inglés, cuenta la imposibilidad de recordarlo todo. Y, sin embargo, pese a la dificultad del recuerdo, el narrador relata cómo comenzó el día. Sonó la diana de noche. Poco a poco salieron los viejos, los enfermos. Tenían miedo. Mucho ruido, y mucha, mucha angustia. Una voz, un grito, en alemán, da órdenes. El sargento nazi y sus hombres golpean a todo el mundo, entre lamentos de dolor. El sargento ordena numerarse. El sargento quiere saber, en un minuto, a cuántos va a enviar a la cámara de gas... Y, de repente, todos juntos, cantan el Shema Yisrael. Esta es la segunda parte de la obra. Es la expresión de la esperanza frente a la catástrofe. En medio del horror, la fe, en el infierno, la esperanza.

\subsection{Cine}

Auschwitz ha sido tratado de diversas y muy diferentes películas. ${ }^{23}$ La última etapa, película polaca estrenada en 1948 y dirigida por Wanda Jakubowska; Nuit et Brouillard (1955) de Alain Resnais; The Diary of Ann Frank, adaptación cinematográfica de 1959 de Francis Goodrich y Albert Hackett de su propia obra teatral; Kapo, película italiana realizada en 1960 por Gillo Pontecorvo; La Pasajera, film polaco de 1962, dirigido por Andrzej Munk; La lista de Schindler (1993), de Steven Spielberg, La vida es bella (1999) de Roberto Benigni, o la más reciente El tren de la vida (2000) de Radu Mihaileanu son ejemplos más que evidentes de la enorme importancia que Auschwitz ha tenido para el cine. Pero entre todas las películas, creemos que es Shoah (1974-1985), de Claude Lanzmann, la obra más representativa del tema que nos ocupa.

Shoah no es una película corriente. Lanzmann dedicó once años de su vida a la elaboración del film. "Las cifras son impresionantes por sí mismas: 350 horas de material rodado, cinco años y medio para terminar el montaje" 24 .

No hay en ella ni ficción, ni documentos de archivo, ni recreación de escenarios. No es un documental. Shoah es una película oral, en la que el director, Claude Lanzmann, busca supervivientes de los campos por todo el mundo, y les invita a volver al lugar del que sobrevivieron, a recordar, hoy, desde hoy, lo que allí sucedió.

Shoah es la película que muestra la importancia del silencio al que antes nos referíamos. Es una película oral y silenciosa, es una película pudorosa. A diferencia de La lista de Schindler, ${ }^{25}$ Shoah muestra la huella, la ausencia, el vacío. ¿Cómo poder imaginarse lo inimaginable? ¿Cómo poder hablar de lo inexpresable? Este es el reto que Lanzmann nos propone con su película, y la invitación dolorosa, en ocasiones terriblemente dolorosa, -como es el caso del peluquero Abraham Bomba- a recordar. Bomba recuerda, desde Israel, cómo cortaba el pelo a las mujeres que inmediatamente después entrarían en la cámara de gas de Treblinka. Y narra de historia de un compañero suyo, que se encontró, entre ese grupo de mujeres, a su esposa y a su hermana. De repente, Bomba se calla, enmudece. Silencio. Solamente unas breves lágrimas. El director, Lanzmann, le ruega que siga narrando, recordando. "Es necesario", le dice. Y Bomba, finalmente, continúa. Sin embargo, el espectador ha experimentado el silencio de Abraham Bomba. Un silencio que comunica más que las palabras, que no dice, que muestra.

Los personajes de Shoah son supervivientes judíos, pero también personas que vivían junto a los campos, polacos, alemanes, y que asistieron, impasibles, al genocidio. Junto a ellos son estremecedores los relatos de los verdugos, las descripciones de la llegada al campo, la selección, el gaseamiento... Lugares, voces, rostros: el arte de Lanzmann consiste en hacer hablar 
a los supervivientes hoy, en los lugares en los que sucedió el horror, pero con el aspecto actual. Se trata de resucitar el recuerdo a través del espacio, un espacio que ha cambiado, y que desvela la memoria, el tiempo.

Sin embargo, no todo han sido alabanzas para Shoah. Tzvetan Todorov ha criticado la película en su libro Frente al límite. Para Todorov, Shoah no es un documental, sino una obra de arte. Esto no es una crítica, sino todo lo contrario, porque al decir que Lanzmann crea una obra de arte y no un documental, Todorov no está negando a Shoah la capacidad "para decirnos la verdad sobre una época y sobre los acontecimientos que se desarrollaron en ella." ${ }^{26}$ Sin embargo, objeta Todorov que, sobre todo en la parte "polaca" de la película, "Lanzmann perfirió mostrarnos solamente polacos antisemitas. Permanecen indiferentes ante el recuerdo de los sufrimientos de los judíos, mantienen siempre los mismos estereotipos sobre ellos, están contentos en definitiva de haberse desembarazado de ellos"27.

La crítica de Todorov se dirige a la diferencia que Lanzmann establece entre el comportamiento de los campesinos franceses y los polacos. Según Todorov, Lanzmann cree que los campesinos franceses "no habrían admitido jamás los campos de exterminio en su país -lo cual quiere decir que los polacos son culpables de haberlos admitido" 28 .

Si uno ve la película probablemente puede pensar que Todorov tiene razón. Sin embargo, considerada globalmente, Shoah es una de las obras de arte más extraodinarias sobre la recepción de Auschwitz en la cultura occidental. Nadie puede pensar después de Auschwitz sin tener presente este film magistral.

\section{Auschwitz como situación educativa radical}

Desde la reflexión pedagógica ${ }^{29}$, la pregunta se puede formular de distintas formas, pero todas ellas inciden en lo mismo: ¿Cómo escribir, leer, educar después del totalitarismo? ¿Qué cultura producir después de Auschwitz? Aquí, la respuesta es una doble exigencia o imperativo: el imperativo de Adorno de que "Auschwitz no se repita" ${ }^{30}$ y la exigencia enunciada por J-F. Forges de "educar contra Auschwitz": "El deber de la memoria no tiene más sentido que conducir a la movilización para la atención y la resistencia sobre el presente y sobre el futuro". 31

La pregunta por esa recepción de lo dramático se tendrá que plantear, como puede verse ya desde el principio, con la máxima exactitud y rigor, pero al mismo tiempo con una sensibilidad extraordinaria, ya que en nuestra memoria se encuentra una identidad humana profundamente lesionada $\mathrm{y}$, además, en esa misma memoria resuena, paradójicamente, la inaudible palabra del niño Hurbinek. Se trata de ese niño nacido en el infierno de Auschwitz a quien, al parecer, el único que tomó en serio, el único que fue capaz de recibirle, a pesar de no entenderle, fue el adolescente Henek.

Como lo ha destacado recientemente Michael Pollack en L'expérience concentrationnaire, el carácter "excepcional" de la "experiencia extrema" de los campos de concentración vuelve problemáticos dos fenómenos centrales a nuestro tema: la identidad y la memoria. La identidad no resulta problemática, ni constituye una preocupación, hasta que el sujeto se ve enfrentado a una situación de radical extranjeridad y ajenidad frente a sí mismo, es decir, salvo en aquellas circunstancias en las que uno no se reconoce y no reconoce el universo extremo al que es aban- 
donado o expulsado. ${ }^{32}$ La identidad de los supervivientes de los campos de concentración es no sólo una identidad herida, sino que además es una identidad profundamente reconstruida y, por así decir, una identidad reformada en un grupo de destino: el superviviente deconstruye en el campo su identidad y luego se asimila al grupo de destino del resto de los supervivientes, teniendo que llevar, fuera del campo, una vida normal, con la identidad anormal de quien se sabe que ha sobrevivido al infierno.

Por otra parte, la mención que hacemos aquí al relato que presenta Primo Levi de Hurbinek en La tregua no es accidental, sino más bien esencial de cara a la formulación de la pregunta por la recepción de Auschwitz en la cultura occidental. ${ }^{33} \mathrm{Su}-$ pongamos por un momento que esa cultura es la cultura del logos, de la razón y de la palabra, y que la figura que lo expresa es, precisamente, el joven Henek. Y supongamos también que Auschwitz está perfectamente expresado en la figura casi paralítica de Hurbinek el niño, el infans carente de palabra. El encuentro entre uno y otro es un encuentro singular. Se trata, claro está, de un encuentro pedagógico, en el que alguien recibe a alguien (Henek a Hurbinek). Y la situación a la que nos enfrentamos es una situación educativa radical. Con toda la seriedad del mundo, sin dar lugar a sensiblería alguna, Henek, el adolescente dotado de palabra, acoge la palabra por venir y todavía no dicha de Hurbinek. Con toda la seriedad del mundo, Henek trata al pequeño Hurbinek como si lo entendiese, como si fuese capaz de decir la palabra que todavía no ha pronunciado, la voz de la que es incapaz aún.

En un bellísimo y atinado texto, pedagógicamente esclarecedor, Phillipe Merieu, actual director del Centro Nacional de Investigación Pedagógica de París, ha perfilado esta situación educativa radical que supone el encuentro de Henek y Hurbinek. ${ }^{34}$ Nuestra tesis es que este encuentro define las condiciones bajo las cuales, ya en términos más generales, la cultura occidental debería recibir o acoger el acontecimiento brutal de Auschwitz. Porque Henek, que no tiene sin duda vocación educadora alguna, se comporta como lo haría un verdadero educador: le trata más maternalmente que paternalmente, atiende sus necesidades materiales con manos hábiles que no sienten repugnancia, y, sobre todo, espera; tiene una confianza especial en que Hurbinek acabará hablando: se lo toma en serio, como hemos dicho. Le habla, y al hablarle sin cesar, Henek reconoce en Hurbinek a un ser humano, aunque este sea incapaz de decir nada. La palabra de Henek, una palabra que Hurbinek no puede comprender, es una palabra destinada a reconocer en él su condición de ser humano. Esa palabra de Henek es una palabra de reconocimiento de la humanidad del pequeño Hurbinek, el infante sin palabra. Es una palabra que cura, una palabra que da la palabra, que permite la palabra, que se abre y busca otra palabra, como quien sale al encuentro de lo que más se ama. Una palabra que acoge y transmite el silencio de Hurbinek.

En este sentido, la educación, tal y como queda esta derivada del encuentro entre un niño y un adolescente, del encuentro entre la palabra muda y la palabra ya adquirida, no es otra cosa que la voluntad por hacer un lugar al otro dentro de uno, aunque sea al precio de la propia deconstrucción del propio yo, pero aceptando que este lugar de acogimiento no está ni previsto ni programado. Es buscar y desear que surga la palabra en el otro, que el otro encuentre su propio modo de expresión, sin dictar la palabra que deba decir desde un a priori. Educar es, en fin, justo lo contrario del totalitarismo. Comentando este texto de Merieu, Alain Finkielkraut señala en Une voix que vient de l'autre rive que 
enseñar, después de Auschwitz, es abrirse, y no simplemente transmitir; en vez de comunicar un saber por medio de la palabra, es el empeño por hacer surgir en el otro una palabra que no se puede dictar desde ningún sitio previamente concebi$\mathrm{do}^{35}$.

Lo que se desencadena en este singular encuentro es una experiencia de donación, es una experiencia de recepción, es una experiencia de acogimiento del otro, y todo el misterio de la espera de la palabra del otro, en las condiciones más extremas y menos apropiadas para que palabra alguna se pronuncie, como un homenaje al reconocimiento de la humanidad del sujeto al que se le había negado humanidad alguna.

\section{NOTAS}

${ }^{1}$ Como señala Enzo Traverso: "una ruptura de humanidad y un desgarramiento de la historia, sin duda el más profundo del siglo" (Traverso, E. (1997): L'Histoire déchirée. Essai sur Auschwitz et les intellectuels, París, Cerf, pág. 10).

2 Weinrich, H. (1999): Leteo. Arte y crítica del olvido, Madrid, Siruela, pág. 351: "En toda introducción a la actividad científica, es decir, en la enseñanza universitaria, se debería enseñar -cosa que hasta ahora no ocurre-, además de las imprescindibles técnicas de adquisición de información, también el sutil arte de rechazar informaciones. Porque la ciencia ya no es practicable hoy sin un claro componente de olvido."

${ }^{3} \mathrm{O}$ lo que es lo mismo: vivimos insertos dentro de una tradición simbólica, cuyas limitaciones probablemente debemos aprender a superar, pero justamente por ello, porque no es elegible ni el tiempo ni el espacio en que vivimos, debemos aprender a vivir teniendo detrás todo lo negativo que Auschwitz, como tradición que encarna el mal, contiene. Es necesario recordar lo que sucedió en Auschwitz para poder extraer de allí una lección ética. Sobre este tema, en relación al principio antropológico de la contingencia, ver: Marquard, O. (1986): Apologie des Zufälligen, Reclam, Stuttgart. [Trad. cast. Apología de lo contingente, Valencia, Alfons el Magnànim, 2000].

${ }^{4}$ Bauman, Z. (1998): Modernidad y Holocausto, Madrid, Sequitur.

5 Sobre la interpretación de Auschwitz como un cierto acontecimiento "educativo" de orden radical pueden extraerse interesantes reflexiones de la lectura de los textos siguientes: Finkielkraut, A. (2000): Une voix vient de l'autre rive, París, Gallimard; Merieu, Ph. (1995): Mémoire et vigilance: quelle éducation?, Soirée Débat à Belley (Ain), 6 avril 1995.

${ }^{6}$ Le Breton, D. (1997): Du silence, París, Métailié.

7 Celan, P. (1994): “Argumentum e silentio", en De umbral en umbral, Madrid, Hiperión, pág. 109. (Trad. de Jesús Munárriz).

${ }^{8}$ Magris, C. (1999), El Danubio, Anagrama, Barcelona, pág. 131 .
9 Ver Le Breton, D. (1997): "Politiques du silence", en Du silence. Essay, ed. cit., págs. 77-114

${ }^{10}$ Mate, R. (1999): "Epílogo para los que vivimos después de Auschwitz", en De Atenas a Jerusalén. Pensadores judios de la Modernidad, Madrid, Akal, pág. 75: "Hay un antes y un después de Auschwitz. Lo que caracteriza al hombre de después, es decir, a nosotros mismos, es la incapacidad de recordar debidamente, como si entre los daños irreversibles inferidos al ser humano hubiera estado la destrucción de la memoria. Para el hombre de después es fundamental la referencia al tiempo, por dos razones: en primer lugar, para apropiarse de un instrumento analítico (me refiero al Nuevo Pensamiento) que fue acertado a la hora de denunciar el peligro latente de los tiempos que corrían y que puede serlo hoy, ya que seguimos pensando igual que antes, como si nada hubiera ocurrido; $\mathrm{y}$, en segundo lugar, para reencontrar la memoria: puesto que no somos capaces de recordar, empecemos por conocer qué significa hablar de memoria."

${ }^{11}$ La recepción de Auschwitz en el ámbito literario es enorme. Véase a título de ejemplo, puesto que no trataremos específicamente este campo, sino que nos centraremos únicamente en la poesía y concretamente en la obra de Paul Celan, los títulos siguientes: Wardi, Ch. (1986): Le génocides dans la fiction romanesque, París, PUF; Young, J. E. (1988): Writing and rewriting the Holocaust. Narrative and the consequences of interpretation, Bloomington-Indianapolis, Indiana University Press.

${ }^{12}$ Molinuevo, J. L. (1998): El espacio político del arte. Arte e historia en Heidegger, Madrid, Tecnos., pág. 65.

${ }^{13}$ Forges, J-F. (1997): Éduquer contre Auschwitz. Historire et mémoire, ed. cit., pags. 13-14.

${ }^{14}$ Como señaló Raoul Hilberg, se trata de "una recreación tal representa un acto de creación en sí". Véase Hilberg, R. (1996): La politique de la mémoire, París, Gallimard, pág.79.

15 Kertész, I. (1999): "Le vingtième siècle est une machine à liquider permanente", en Coquio, C. 
(comp.) Parler de camps, penser les génocides, ed, cit., pág. 88 .

${ }_{16}$ Citamos el poema por la reciente edición de las obras completas editadas por Trotta. Celan, P. (1999): Obras Completas, Madrid, Trotta. Prólogo de Carlos Ortega y traducción de José Luis Reina. Edición bilingüe. También hemos tenido presente la edición de Hiperión: Celan, P. (1996): Amapola y memoria, Madrid, Hiperión, tercera edición revisada. Traducción y notas de Jesús Munárriz, edición bilingüe.

17 Ortega, C. (1999): "Prólogo. Que nadie testifique por el testigo", en Paul Celan. Obras Completas, ed. cit., pág. 21

18 Traverso, E. (1997): "Paul Celan et la poésie de la destruction”, en L'Histoie déchirée, ed. cit., pág. 147. Sobre la cuestión de los límites de lo decible en la obra de Paul Celan resulta muy sugerente leer el artículo de Ricardo Forster, "El imposible testimonio: Celan en Derrida", Pensamiento de los confines, núm. 8, Buenos Aires, págs. 77-90.

${ }^{19}$ Ortega, C. (1999): "Prólogo. Que nadie testifique por el testigo”, ed. cit., pág. 17.

${ }^{20}$ Mayer, H. (1999): Historia maldita de la literatura. La mujer, el homosexual, el judio, Madrid, Taurus, pág. 408

${ }^{21}$ Zoran Music nació en Görtz, en 1909, en la Austria del imperio Austro-Húngaro. Debido a la inestabilidad geopolítica y militar, estuvo en contacto con diferentes lenguas y culturas, principalmente la eslovena, la alemana y la serbocroata. A los veinte años conoce el paisaje de la Dalmacia, que resultará una fuente temática principal de su pintura, y en 1935 viaja a España, donde encontrará dos fuentes temáticas más de inspiración en su obra: la meseta castellana y el genio trágico de Goya. En 1944 es detenido por los nazis, por sus ideas antifascistas, y deportado al campo de concentración de Dachau, donde conseguirá sobrevivir hasta la liberación en 1945

${ }^{22}$ Music, Z. (2000): "El arte después de Dachau", ABC Cultural, 18 de marzo de 2000, págs. 31-33. Todas las citas de Music corresponden a este texto

${ }_{23}$ Sobre la recepción de Auschwitz en el cine, véase Avisar, I. (1988): Screaning the Holocaust. Cinema's images of the inimaginable, Bloomington-Indianapolis, Indiana University Press, Insdorf, A. (1985): L'Holocauste à l'écran, París, Cerf.

${ }^{24}$ Sánchez-Biosca, V. (1999): "Hier ist kein warum. A propósito de la memoria y la imagen de los campos de la muerte", en La memoria de los campos. El cine y los campos de concentración, Valencia, Ediciones de La mirada, pág. 28.

${ }^{25}$ Sobre la crítica a La lista de Schindler, véase R. Forster, "El ojo impúdico", en El exilio de la palabra, Buenos Aires, Eudeba, 1999.

${ }^{26}$ Todorov, T. (1993): Frente al límite, México, Siglo XXI, pág. 278.

${ }_{27}$ Todorov, T. (1993): Frente al límite, ed. cit., pág. 279. 280.

28 Todorov, T. (1993): Frente al límite, ed. cit., pág.

${ }^{29}$ Sobre los peligros de una pedagogización de Auschwitz, como objeto de aprendizaje, ver: Schnur, E. (1997) Pédagogiser la Shoah?, Le Télémaque, no 9, pp. 5-20. Sobre la enseñanza de Auschwitz y el tratamiento pedagógico del Holocausto ver, además: Traverso, E. (1995): Insegnare Auschwitz. Questiones etiche, storiografiche, educative della deportazione e dello sterminio, Turin, Bollati-Boringhieri; Forges, J-F.(1997): Éduquer contre Auschwitz: histoire et mémoire, ed. cit.; Short, G., Supple, C. y Klinger, K. (1999): L'Holocauste dans les programmes scolaires: un point de vue européen, Bruselas, Ëditions du Conseil de l'Europe; Supple, C. (1991): The teaching of the nazi Holocaust in North Tyneside, Newcastle and Northumberland Schools, Rapport; Supple, C. (1993): From prejudice to genocide - learning about the Holocaust, Trentham Books; Langeweld, W. (1981): Holocaust: its meaning for political education, International Journal of Political Education, vol. $4, \mathrm{n}$ - $1-2$.

30 Adorno, Th. (1998): "Educación después de Auschwitz", en Educación para la emancipación, Madrid, Morata, pág. 79

${ }_{31}$ Forges, J-F. (1997): Éduquer contre Auschwitz, ed. cit., pág. 150

32 Pollack, M. (2000): L'expérience concentrationnaire, ed. cit., pág. 10

${ }^{33}$ Levi, P. (1997): La tregua, Barcelona, Muchnik, cuarta edición, págs. 21-23

${ }^{34}$ Merieu, Ph. (1995): Mémoire et vigilance: quelle éducation?, ed. cit., citado en: J-F. Forges (1997) Éduquer contre Auschwitz: histoire et mémoire, ed.cit., págs. 124-125. Ver también el espléndio ensayo de Forster, R. (1999): "Hurbinek: la palabra inaudible o el decir después de Auschwitz", en El exilio de la palabra. En torno a lo judio, ed. cit., págs. 237-246

${ }^{35}$ Finkielkraut, A. (2000): Une voix vient de l'autre rive, ed. cit., pág. 118 . 